\title{
The influence of diet on protein oxidation
}

\author{
Helen R. Griffiths \\ Pharmaceutical Sciences Research Institute, Aston University, Aston Triangle, \\ Birmingham B4 7ET, UK
}

\begin{abstract}
Protein oxidation can be perceived as essential for the control of intracellular signalling and gene expression on the one hand, but in contrast, a potentially cytotoxic hazard of aerobic life. Reduction and oxidation of thiol groups on specific cysteine residues can act as critical molecular switches, in modulating response to growth factors, apoptotic and inflammatory stimuli to name a few. Such oxidative reactions are likely to be transient and represent low levels of oxidative modification to a protein. Sustained oxidative stress conditions through absence of essential dietary antioxidant or low activity of endogenous enzyme scavengers can cause irreversible damage and loss of function. Such modifications are believed to be important in many diseases associated with ageing. Therefore, it has been postulated that diet may exert an influence on the steady state of protein oxidation and thus offer potential health benefits through preservation of normal protein function. In the present paper, the current evidence from in vivo studies on the effects of dietary antioxidants and oxidants on protein oxidation will be evaluated, and needs for future research will be highlighted.
\end{abstract}

Thiol: Antioxidants: Signalling: Lens opacity: Low-density lipoprotein

\section{Introduction}

An increased intake of fruit and vegetables is associated with reduced risk of cardiovascular disease and certain cancers. This association has been attributed to the presence of dietary antioxidants within these foodstuffs, and their protective effects against macromolecular oxidation (Marchioli, 1999; Methta, 1999; Tribble, 1999).

In the past decade several large studies have been undertaken to evaluate the beneficial effects of antioxidants taken in isolation or in combination on both hard disease endpoints, i.e. cancer, cardiovascular disease, and primary endpoints including reduction of oxidised biomolecules, such as lipid, DNA and protein (Stephens et al. 1996; GIZZI Prevenzione Investigators, 1999; Aviram, 2000; Carty et al. 2000; Loft \& Poulsen, 2000). Of these, antioxidant effects on protein oxidation in vivo has been the least studied.

Corresponding author: Dr H. R. Griffiths, fax +44 121359 0733, email h.r.griffiths@ aston.ac.uk 
The present review will focus on published evidence for the modulation of protein oxidation in vivo, in both studies with human subjects and animal studies. The data will be critically appraised in the light of recent consideration of the intracellular effects of vitamins $\mathrm{C}, \mathrm{E}$ and flavonoids.

\section{Are proteins important targets for oxidants?}

Proteins make up more than $65 \%$ of the dry weight of most cells and this percentage increases in certain tissues such as the lens. Furthermore, aromatic and sulfur-containing amino acids react with the hydroxyl radical at diffusion-controlled rates (Anbar \& Neta, 1967). Taken together these data indicate that proteins may in fact serve as general antioxidants, able to mop up excessive free radical species including peroxy radicals, peroxynitrite, hypohalous acids and $\mathrm{H}_{2} \mathrm{O}_{2}$ (these species will be collectively considered as mediators of oxidative stress). It has been suggested that methionine in particular may represent a sink for oxidative attack with little consequence for overall function (Levine et al. 1999).

Oxidative damage to proteins can also be associated with modification of protein function. One of the first examples of this damage was demonstrated when studying the effects of selected radicals generated by radiolysis on the enzyme, lysozyme (Adams et al. 1969). Both the thiocyanate radical (a selective modifier of tryptophan) and ${ }^{\circ} \mathrm{OH}$ were found to inactivate the enzyme, implying that tryptophan residues are essential for biological activity, now well established from classical enzymology. Similarly, for $\alpha$-1-antitrypsin, modification of a single methionine residue at position 358 rendered the protein inactive (Carp \& Janoff, 1979). Subsequent hydrolysis and amino-acid analysis revealed the presence of methionine sulfoxide. This was one of the first pieces of evidence linking amino-acid oxidation to denaturation of proteins and loss of function.

The importance of protein oxidation in respect of altered function is further exemplified by formation of Schiff's base products between histidine and lysine in LDL and lipid-derived aldehydes, which causes altered receptor recognition. Whilst native LDL is taken up by endothelial cells via a feedback-controlled receptor-regulated process, oxidative modification of LDL renders it a ligand for many scavenger receptors. Scavenger receptors include CD-36, LOX-1 and the prototypic macrophage SR A I/II, all of which are variably expressed (Steinbrecher, 1999). Uncontrolled uptake of oxidised LDL is implicated in the pathogenesis of atherosclerosis. Few data are available on the effects of specific minor modifications to apolipoprotein B. In order to identify the sequence specificity and nature of oxidative modifications that confer altered properties on LDL, we have previously described the effects of modified peptides corresponding to the putative LDLR binding domain on LDL uptake by human umbilical vein endothelial cells and U937 monocytes (Griffiths et al. 1999). These data showed that modification of LDL by non-covalent interaction with malondialdehyde-peptide altered recognition of LDL by U937 cells. This evidence supports the hypothesis that limited modification to lysine using malondialdehyde has a functional effect on LDL uptake. In addition, oxidised LDL increases chemokine receptor 2 protein and mRNA expression on monocytes, and thus may contribute to monocyte retention and perpetuation in inflammatory, unstable atherosclerotic lesions (Weber et al. 1999). It remains to be determined whether dietary antioxidants are effective at inhibiting functional changes by oxidative stress in relation to LDL uptake. Recent work from Azzi's group has shown that $\alpha$-tocopherol can inhibit the CD36 scavenger receptor mechanism in vitro via a protein kinase $\mathrm{C}$, antioxidant-independent mechanism, indicating a dual route of benefit from $\alpha$-tocopherol (Riciarelli et al. 2000). 
Oxidative modifications to proteins may also act as molecular switches, turning on downstream effects. Protein thiol groups on protein-bound cysteine residues are increasingly recognised as having critical roles in receptor function, signal transduction and transcription factor activation. Membrane-associated Ca-ATPase is an active transporter of $\mathrm{Ca}$ against concentration gradients, to maintain low levels of intracellular $\mathrm{Ca}$ in resting cells. However, this activity is dependent on a redox-active thiol, which can be disrupted by oxidative stress, for example in sarcoplasmic reticulum Ca-ATPase (Viner et al. 2000). This may be important in oxidative signalling to cell death via apoptosis which is partially dependent on activation of Ca-dependent ATPases.

\section{Evidence for oxidation in protein phosphatase and kinase cascades}

Phosphorylation cascades are involved in transducing the signals of many extracellular stimuli to the nucleus. Oxidant treatment of cells is widely reported to affect activities of protein kinases and the levels of protein phosphorylation (Abe et al. 1997; Hardwick \& Sefton, 1997; Ruff \& Chen et al. 1997). Components of the mitogen-activated protein kinase cascade, an important signalling pathway in growth activation, contain redox-sensitive sites, thus providing the potential for modulation via cellular redox status. Indeed, reactive oxygen species can activate mitogen-activated protein kinase via a Ras-dependent mechanism (Rao, 1996; Aikawa et al. 1997; Qin et al. 1997). NO can react with cysteine 118 on the surface of Ras to generate a nitrosothiol, which in turn activates the associated G protein activity (Lander et al. 1996, 1997).

Protein phosphorylation is balanced by the effects of specific phosphatases that act to remove protein-bound phosphate groups and reverse the biological effect. Serine threonine and tyrosine phosphatases are known to be redox-sensitive (Nemani \& Lee, 1993; Wang et al. 1996). Phosphatases also contain a redox-sensitive thiol, where the catalytic domain contains a conserved motif with a single cysteine residue. This contrasts sharply with the effects of reactive oxygen species on protein phosphatase CL100, where oxidative stress has been shown to be a potent activator (Keyse \& Emslie, 1992). This enzyme brakes the mitogen-activated protein kinase cascade by dephosphorylating mitogen-activated protein kinase, and thus exerts a regulatory loop on the pathway under situations of oxidative stress.

The protein kinase $\mathrm{C}$ family of proteins is subject to increased activity following oxidative attack. Selective oxidation within the amino terminal domain, which contains a Zn-thiolate structure, can activate the pathway, whereas oxidation of the carboxyl terminal by higher concentrations of reactive oxygen species inactivates the enzyme (Gopalakrishna \& Anderson, 1987, 1989).

\section{Evidence for protein oxidation in transcription factor, nuclear factor $\kappa$ B and activator protein 1 activation}

Nuclear factor к B is the prototypic model of a redox-sensitive transcription factor (Schreck et al. 1992; Li \& Karin, 1999), where its downstream effects modulate expression of many inflammation, apoptosis and growth-promoting genes. Normally retained on the cytoplasm in an inactive complex with inhibitor $\kappa \mathrm{B}$, the protein is released following phosphorylation of the inhibitor complex. This reaction is catalysed by either of two redox-sensitive inhibitor $\kappa$ kinase proteins, which contain a cysteine residue in the kinase domain that is essential for function

(Gius \& Botero, 1999). However, whilst oxidising conditions promote the transduction of 
nuclear factor $к \mathrm{~B}$ from cytoplasm to nucleus, the activity of the transcription factor depends on reducing conditions within the nucleus. The Se-dependent protein thioredoxin reductase has a key role to play, indicating the importance of dietary Se in effective gene transcription (Mitomo et al. 1994; Powis et al. 2000).

Activator protein 1 can be controlled by levels of both oxidants and antioxidants (Manna et al. 1998; Dalton et al. 1999). The reasons for these contradictory data are unclear. However, it is clear that fos and jun components of activator protein 1 must maintain thiol residues on cys154 and cys-272 respectively for cellular activity (Xanthoudakis \& Miao, 1992).

For the most part, subtle changes in local redox state are crucial for signalling and gene expression, leading to the question of whether antioxidant effects are always desirable. It is likely that such modifications are sterically restricted away from the effects of hydrogendonating antioxidants, as has been suggested in amino-acid oxidation by Fenton reactions (Stadtman, 1993). It may be suggested that a balance exists between essential oxidative changes for molecular switching during cell signalling, overall scavenging of excessive reactive species and oxidative damage to proteins associated with loss of function. In such a scenario, only protection against the latter may be deemed to be an essential process (see Fig. 1).

\section{Which proteins should be examined for protection against oxidative damage by dietary antioxidants?}

Proteins are distributed in all cellular compartments as well as forming key components of the extracellular matrix (for example, fibronectin) and maintaining the osmotic pressure of plasma (for example, albumin). Whilst this may initially be considered a problem, it can offer advantages over examination of DNA oxidation since it is located in only two compartments, the mitochondrion and nucleus. A similar situation exists with lipids which are present in lipopro-

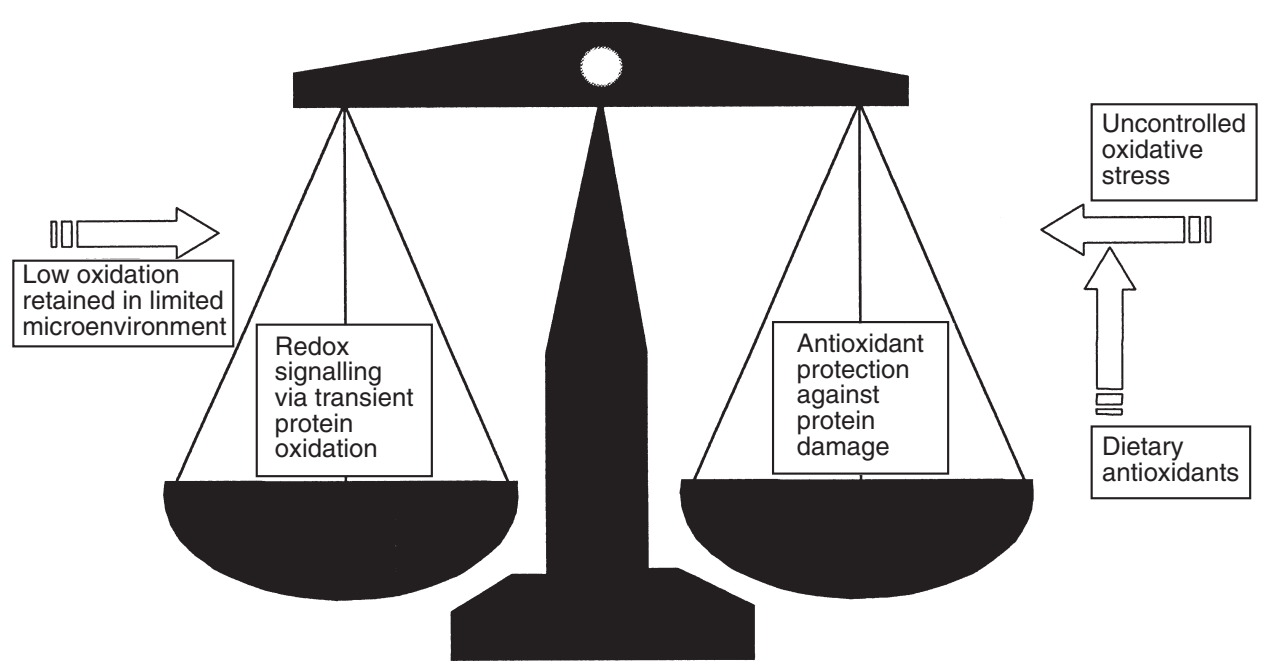

Fig. 1. The balance between biologically acceptable and unacceptable protein oxidation. 
teins and membranes. However, there is no real difference in the rates of reaction of constituent amino acids, bases or fatty acids, all of which react with the hydroxyl radical at diffusioncontrolled rates (Anbar \& Neta, 1967). Instead, the major factors governing which macromolecules are preferential targets appear to be size and proximity to radical source.

The analysis of protein function can also give some indication as to whether oxidation of a particular protein may reflect a useful non-specific scavenging of radicals without consequence for the protein, or in contrast, a deleterious process. Oxidised immunoglobulin $G$ exhibits altered function, in particular through interaction with other effectors within the immune system (Griffiths \& Lunec 1991; Margiloff et al. 1998). Increased Fc receptor activity and C1q binding may promote an inflammatory response, causing further local tissue damage. The oxidative modification of apolipoprotein B, the major protein in LDL, is believed to contribute to its atherogenic potential in vivo (Steinberg et al. 1989; Steinbrecher et al. 1990; Witzum $\&$ Steinberg, 1991). Further studies which address the effects of oxidative stress on sequencespecific amino acids within proteins will facilitate an analysis of whether certain residues can act as useful non-specific scavengers without effect on function.

Intracellular protein oxidation is maintained at a tolerable low level via the $20 \mathrm{~S}$ proteosome, which specifically degrades oxidatively modified proteins. However, if cells are subject to high reactive oxygen species and reactive nitrogen species flux, the proteins may become aggregated and escape $20 \mathrm{~S}$ clearance. Whilst oxidative stress itself may inactivate the ubiquitin proteosomal apparatus, the 20S proteosome is spared (Reinheckel et al. 1998).

Another consideration, which can be made in examining the protective effects of antioxidants against protein oxidation, is the half-life of the protein. Glycation of haemoglobin A1c is considered a good long-term index of glycaemic control in diabetics as haemoglobin has a half-life of 6 weeks. Similarly, a temporal index of oxidative stress and antioxidant protection may be determined from the study of a protein with a long half-life (Griffiths, 2000). It is evident that we are not in a position to be able to select an 'ideal' protein for analysis, and further work is required in this area.

\section{Radical charge transfer from proteins}

The oxidation of a protein should not be considered as the endpoint of oxidative damage. Instead, proteins have important roles both as radical generators and radical transfer molecules.

The energy emitted by u.v. light is insufficient to cause photolysis of water. Rather u.v. light mediates its oxidative damage through direct excitation of susceptible amino acids, such as tryptophan, in the presence of molecular oxygen. Subsequent charge transfer to dissolved oxygen in the aqueous environment results in elevated $\mathrm{H}_{2} \mathrm{O}_{2}$ concentrations in the immediate environment of the protein (Robinson et al. 1998). Similarly, singlet oxygen can be generated from photosensitisation of tryptophan (Singh et al. 1984).

Protein-bound glucose can undergo glycoxidation, whereby the autoxidation of sugar via dicarbonyl residues generates superoxide radicals adjacent to the protein backbone. Free sugars may also undergo autoxidation in the presence of catalytic metal ions. Elevated plasma concentrations of glucose in diabetes are believed to contribute to enhanced oxidative stress through these processes although the relative importance of the two pathways remains to be elucidated (Krapfenbauer et al. 1999).

Elegant studies by Hazell et al. (1999) demonstrate the transfer of radicals following primary attack of apolipoprotein B by hypochlorous acid, onto the lipid moiety in a second step involving homolytic reactions from lysine-chloramines. Histone proteins play a central role in 
protecting and organising nuclear DNA; however, it is also susceptible to the effects of oxidative attack resulting in the formation of hydroperoxide species. Radicals generated during $\mathrm{Cu}$ catalysed degradation of hydroperoxides react with both pyrimidine and purine bases (Luxford et al. 1999, 2000). Similarly protein-bound 3,4-dihydroxyphenylalanine can promote further radical-generating events, transferring damage to DNA (Morin et al. 1998).

\section{What products are formed from oxidative damage to proteins?}

The process of protein oxidation frequently introduces new functional groups, such as hydroxyls and carbonyls, which contribute to altered function and turnover. Improved characterisation of the effects of protein oxidation has identified a spectrum of secondary effects including fragmentation, crosslinking and unfolding, which may accelerate or hinder proteolytic and proteosome-mediated turnover, according to the severity of oxidative damage (Grune \& Davies, 1997). Crosslinks may arise from formation of interchain disulfide bridges, and associated loss of free thiols. The determination of total protein thiols, and of protein carbonyl formation are considered to be generic markers of oxidation, and have been frequently applied biomarkers.

The complexity of protein structure, comprising the primary sequence and involvement of carbohydrate moieties in structure stabilisation, together with a lack of specific and sensitive methodologies has hindered the development of oxidative biomarkers (Davies et al. 1999; Griffiths, 2000). More recently, interest has focused on the analysis of specific protein-bound oxidised amino acids. Of the twenty-two amino acids, aromatic and sulfydryl-containing residues have been regarded as being particularly susceptible to oxidative modification following hydroxyl or peroxy radical attack, with L-3,4-dihydroxyphenylalanine arising from tyrosine oxidation; ortho-tyrosine from phenylalanine, sulfoxides and disulfides from methionine and cysteine respectively, and kynurenines from tryptophan. In addition, specific products of tyrosine can be formed from hypohalous acid attack, for example chlorotyrosine, and from peroxynitrite attack, 3-nitrotyrosine. Latterly, the identification of valine and leucine hydroxides, reduced from hydroperoxide intermediates, has been described and applied (Fu et al. $1995 a, b)$. Lysine can also undergo limited attack at the $\mathrm{C}_{6}$ atom to yield the corresponding aldehyde, adipic semi-aldehyde. The author has recently evaluated the relevance of these, and methods for their analysis have been described elsewhere (Griffiths 2000; Griffiths et al. 2000).

\section{Which dietary components are active in modulating protein oxidation?}

The steady state of oxidised protein within an organism reflects both the level of damage induced and the rate of removal. Therefore, any dietary component that affects oxidative stress, antioxidant capacity or enzymic degradation is a potential modulator. A recent study in rats demonstrated that supplementation with diets rich in protein carbonyls had no effect on the levels of plasma protein carbonyls in the animals, indicating that dietary intake of oxidised protein does not contribute to the measurable steady state of oxidised protein in plasma. Ingestion of $\mathrm{Fe}$, however, was shown to increase protein carbonyl content, presumably by increasing $\mathrm{Fe}$ availability to catalyse the Fenton reaction (Srigiridhar \& Nair, 2000).

Table 1 describes the circumstantial evidence for increased oxidative stress in disease, where increased markers of protein oxidation are found alongside reduced antioxidant status. Classical hydrogen-donating antioxidants such as ascorbate, tocopherols and flavonoids have 
Influence of diet on protein oxidation

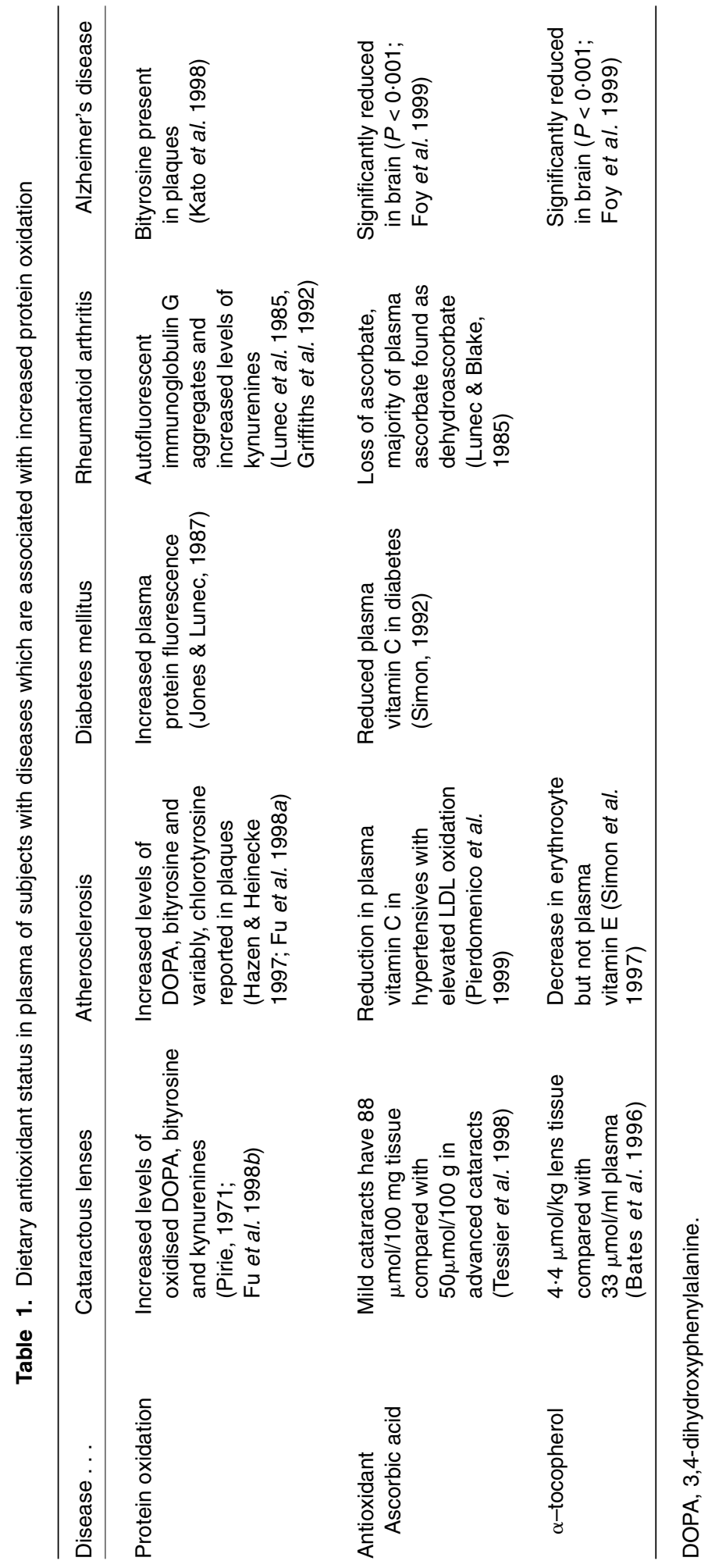


been shown to be effective in protecting against oxidative protein damage using in vitro model systems, and as such may be expected to have a beneficial role in protection against ageingrelated disease. The effects of these antioxidants taken in the diet on protein oxidation are now addressed.

\section{Effects of dietary antioxidants on protein carbonyl status}

We and others have developed an ELISA procedure for quantitative analysis of carbonyl content on specific proteins (Buss et al. 1997; Carty et al. 2000). This offers the advantages of sensitivity, small sample volume, reproducibility and large sample throughput. Bearing in mind the caveat that protein carbonyls are a generic marker of oxidation, they appear to be yielding useful information as biomarkers of protein oxidation. They are positively correlated with age, and the accelerated ageing condition Werner's syndrome is associated with much greater levels of plasma protein carbonyls than would be expected on the basis of age alone (Stadtman \& Oliver, 1991). We have recently completed a study where a protective effect against protein oxidation following long-term (15-30 weeks at $400 \mathrm{mg} / \mathrm{d}$ ) vitamin $\mathrm{C}$ supplementation is observed (Carty et al. 2000). In phase I of the study, we examined the response to supplementation in those who had normal ascorbate concentrations, compared with a second group that had a significantly $(P<0.01)$ lower baseline ascorbate status. We noted no significant effect of placebo, where carbonyl content was not affected over a 5-week period. This indicates immunoglobulin carbonyl status remains fairly stable and is not subject to significant interference from diet or pathophysiological processes such as inflammation. However, vitamin $\mathrm{C}$ supplementation had no significant effect on carbonyl content after 5 weeks, compared with placebo or baseline. This lack of effect may arise from the lack of complete protein turnover over 5 weeks or a more complex response to ascorbic acid. This was followed by a significant reduction in plasma immunoglobulin carbonyl content after supplementation with ascorbic acid for 10 and 15 weeks for those with low baseline ascorbate only. A second supplementation phase was undertaken following a double-blind, randomised split of the subjects in order to counter any seasonal variation in antioxidant consumption.

Within 5 weeks of withdrawal from vitamin $\mathrm{C}$ supplementation onto placebo, immunoglobulin carbonyl levels were significantly higher than in the active supplemented group $(P<0 \cdot 01)$. This finding confirms that the active supplementation is modifying protein oxidation in vivo. The protective effect was maintained as supplementation continued $(P<0 \cdot 05)$, but was removed at washout demonstrating the reversibility of the effect, when neither group was receiving active supplementation.

These data support the hypothesis that ascorbate acts as a scavenging antioxidant in the context of physiological immunoglobulin oxidation. In contrast to the effects previously reported on DNA, no evidence for a pro-oxidant effect was observed on proteins (Podmore et al. 1998). However, this study adopted a dosing regimen of $400 \mathrm{mg} / \mathrm{d}$ whereas our previous study supplemented with $500 \mathrm{mg} / \mathrm{d}$. Antioxidant dose is likely to be an important factor in determining outcome. In addition, duration of supplementation may affect the outcome.

An overall weak negative correlation between ascorbate and immunoglobulin $\mathrm{G}$ carbonyl content was observed $(r-0 \cdot 145, P=0 \cdot 019)$. Recently, we have undertaken partial analysis of the samples from the ASAP study (Porkkala-Sarataho et al. 2000), and have shown a significant inverse correlation between vitamin $\mathrm{C}$ and protein carbonyl status $(r-0 \cdot 575, P<0 \cdot 001)$. The latter study was undertaken over a 12-month period, compared with a 15 -week period in the former. This again lends support to the hypothesis that longer supplementation periods may 
show greater benefit, and is intrinsically linked to protein half-lives and modulation of turnover rate.

Wander \& Du (2000) have examined the antioxidant effect of vitamin E (0, 100, 200 and $400 \mathrm{mg}$ ) in supplementation with $2.5 \mathrm{~g}$ eicosapentaenoic and $1.8 \mathrm{~g}$ docosahexaenoic acids. The fish oil had no effect on protein carbonyl content, nor was the presence of $400 \mathrm{mg} \alpha$-tocopherol in the diet a modulator of plasma protein carbonyl formation. This study evaluated total plasma protein carbonyl content, although it is likely from the hydrophobic nature of $\alpha$-tocopherol, that it may only offer protection against oxidation in lipophilic microenvironments such as LDL or membranes.

The effects of dietary Se on protein oxidation (as carbonyls) in preterm infants has been described (Winterbourne et al. 2000). This study group (173 preterm infants, with birth weight less than $1500 \mathrm{~g}$ ) were randomised to receive Se supplements, and plasma samples were collected at 7 and $28 \mathrm{~d}$ after birth, and at 36 weeks post-menstrual age. Plasma protein carbonyls were significantly higher than for adults, but did not correlate with development of chronic lung disease or retinopathy. Furthermore, levels were not affected by Se supplementation. Oxidative injury at sites such as the lung or retina may be important in prematurity, and markers from such sites may give a more sensitive indicator of outcome and supplementation effects.

Marangon et al. (1999) have described the effect of lipoic acid (600 mg/d, $n$ 16) supplementation in healthy human subjects on measures of oxidative stress, with reference to the effects of $\alpha$-tocopherol (400 IU/d, $n$ 15). After supplementation for 2 months in isolation and a further 2 months of co-supplementation, measures of oxidation were analysed and compared with baseline. Susceptibility to in vitro oxidisability was assessed following incubation with 2,2'-azobis(amidinopropane)dihydrochloride. Lipoic acid was effective in reducing protein carbonyls following in vitro oxidation; an effect that was not mimicked by $\alpha$-tocopherol. This again may reflect the availability of $\alpha$-tocopherol to plasma proteins.

\section{Animal studies of dietary effects on protein carbonyl formation}

There are also reports on dietary antioxidant effects on protein carbonyl formation from animal studies. Supplementation of rat diet with the flavonoid rutin for $18 \mathrm{~d}$ causes a reduction in protein carbonyl content (Funabiki et al. 1999).

Supplementation with $\alpha$-tocopherol or a combination of $\alpha$-tocopherol $(40 \mathrm{mg} / \mathrm{d})$ and ascorbic acid $(24 \mathrm{mg} / \mathrm{d})$ for $15 \mathrm{~d}$ protects against protein carbonyl formation in Fe-deficient rats during Fe repletion (Srigiridhar \& Nair, 2000).

Tocotrienols have been successfully shown to reduce the protein carbonyl levels in the ageing nematode, Caenorhabditis elegans and increase mean life span (Adachi \& Ishii, 2000). Furthermore, they offered protection against oxidative stress induced by u.v. light. These studies are few in number, but are consistent in demonstrating a protective effect against plasma protein oxidation by 'dietary' intervention.

There is a significant requirement for standardisation in the many protocols currently adopted in different laboratories worldwide for the determination of protein carbonyls. This standardisation can be provided through the preparation of a quality assurance material containing defined numbers of carbonyl groups. Such a material could be processed through protein extraction procedures and used to confirm minimal in vitro oxidation. In addition, different protein hydrolysis methods must be examined, to assess efficiency, yield and potential for artifactual induction of oxidised residues. We have demonstrated the stability of protein carbonyls on storage for 3 months at $-80^{\circ} \mathrm{C}$. Such validations are vital before analysis of large numbers of 
samples in a supplementation trial, or indeed in any clinical study. There is also a need for appropriate internal standard material, which is not subject to oxidative variation. Again, this may be addressed through the quality assurance procedures.

\section{Effect of diet on protein thiol status}

The free thiol group of cysteine readily undergoes reversible oxidation to form a disulfide, which can be 'repaired' in the presence of an hydrogen donor such as glutathione. Further oxidation leads to an irreversible oxidation to cysteic acid (Creed, 1984). Oxidation of the single amino acid cysteine is also complicated by the observation that the product may be a composite mixed disulfide. Indeed, in biological systems, the levels of such a product are also indirectly under the influence of inducible enzymes of the glutathione cycle, and thus inherently related to changes in gene expression, conditioning and priming. At present there are no adequate procedures available for assaying mixed disulfide formation, and it is likely that the only adequate methodology may arise from the development of immunological reagents. Analysis of thiols has been undertaken in antioxidant supplementation studies in human subjects (Keenoy et al. 1999; Carty et al. 2000). In an intervention study in diabetics a non-significant increase in sulfydryl status on supplementation was shown (Keenoy et al. 1999), where a similar trend was observed in normal subjects following ascorbate supplementation (Carty et al. 2000). The major contributor to plasma sulfydryl status is albumin, which is turned over within 2-3 d, and oxidation of sulfydryl on other longer-lived proteins may be of greater functional importance. In plasma, measurements are mainly due to the high thiol content of albumin and its associated function in transport of small molecules including interfering drugs such as D-penicillamine. Cellular thiol analysis is confounded by the interrelationship with glutathione and its synthetic enzymes. Indeed, without any measure of oxidised product, thiol analysis should be considered a poor marker.

\section{Influence of diet on plasma 2-amino-adipic semialdehyde residues}

Lysine can also undergo limited attack at the $\mathrm{C}_{6}$ atom to yield the corresponding aldehyde, adipic semi-aldehyde. $\alpha$-Semi-adipic aldehyde is also formed enzymically, and this may confound some determination of this product. Nevertheless, there have been several papers from Denmark in the last 2 years that have adopted this biomarker in normal subjects (Nielsen et al. 1999; Young et al. 1999, 2000). Grape-seed extract, rich in catechins and phenolics, was used as the active supplement for 1 week in fifteen subjects. However no effect was seen on protein oxidation (Young et al. 2000). A second study looked at flavonoid-containing fruit juice in five subjects, again for 1 week at three doses, where the intakes were $4 \cdot 8,6 \cdot 4$ and $9 \cdot 6 \mathrm{mg}$ quercetin/d. In this study, plasma 2-amino-adipic semialdehyde increased with time and dose, indicating a pro-oxidant effect (Young et al. 1999). A third study examined parsley, rich in flavone for 1 week in fourteen subjects, providing 3.73-4.49 mg apigenin/MJ. In this study, no significant changes were observed in plasma protein (albumin)2-adipic semialdehyde residues (Nielsen et al. 1999). The rather inconclusive nature of these studies may be simply a reflection of the lack of statistical power, combined with short duration of supplementation, which must exceed the half-life of the protein for any effects to be detected. 


\section{Antioxidant modulation of antibody reactivity with oxidised low-density lipoprotein}

Native LDL is not immunogenic; however, oxidation and derivatisation via lipid-derived aldehydes can create neo-antigenic determinants. It has been demonstrated that such epitopes can elicit an immunogenic response, with the specific production of autoantibodies. Therefore the titre of anti-ox-LDL antibodies may reflect the level of LDL oxidation in vivo. Similarly, antisera raised to specific epitopes may be a useful reagent in the direct quantitation of oxidised LDL by ELISA. Kato et al. (2000) describe the development of antisera to N(epsilon)-hexanoyl lysine, a novel adduct formed from the interaction between linoleic acid hydroperoxide and lysine. This reagent was subsequently used to evaluate the effects of supplementation with the flavonoid eriocitrin, on skeletal muscle stressed by exercise. A reduction in N(epsilon)hexanoyl lysine was observed in supplemented animals, indicating a protective antioxidant effect.

A recent study in Watanabe heritable hyperlipidaemic rabbits using an antibody against lysine-malondialdehyde examined uptake of radiolabelled antibody into plaques in animals fed diets supplemented with dietary vitamins $C$ and $E$ for 6 months (Tsimikas et al. 2000). Those on normal diets developed lesions rich in modified lysine; however, those fed diets supplemented with vitamins $\mathrm{C}$ and $\mathrm{E}$ showed fewer oxidation specific epitopes (Tsimikas et al. 2000).

\section{Protection by antioxidants against hard disease endpoints}

Crosslinking of crystallin proteins in the lens arising from either glycoxidative changes, or u.v.derived radicals is believed be an important factor in increasing lens opacity with age. Thus, protein oxidation in vivo can be monitored over time in a non-invasive way. The effects of long-term vitamin $\mathrm{C}$ supplement use and prevalence of early age-related lens opacity has been examined in a cohort of 247 women from the Nurses' Health Cohort. In this study, use of vitamin C supplements for greater or equal to 10 years was associated with a $77 \%$ lower prevalence of early lens opacity (Jacques et al. 1997). These data suggest that long-term consumption of vitamin $\mathrm{C}$ supplements may substantially reduce the development of agerelated lens opacity.

\section{Future directions}

It is evident from the body of evidence presented that a 'fingerprint' of the oxidising species present in vivo should be attainable by adopting a broad spectrum of biomarkers which includes valid markers from each class of macromolecules (DNA, lipid and protein).

There are several techniques and markers with the requisite sensitivity and specificity to be applied in the evaluation of dietary antioxidants. But what proteins should we study? Is there a difference between the ability of different antioxidant classes to protect plasma proteins compared with cellular proteins? What is the subcellular distribution of protein oxidation? How is the breakdown of oxidised proteins via the proteosome affected by antioxidants? Protein sequence information on databases such as Swiss PROT (http://www.expasy.ch/sprot/sprot-top.html), may ultimately allow us to predict susceptible proteins and residues, based on our knowledge of tertiary structural and secondary sequence susceptibility patterns. Together with the advances in proteomics, our understanding of the differential susceptibility of proteins to oxidative insult will be further enhanced. The present paper has highlighted the advantages of adopting several biomarkers for studying in vivo oxidation of proteins and these methods should now be carefully 
applied using quality assurance material to controlled studies of antioxidant intake, to evaluate the significance of dietary antioxidants in preventing physiological oxidative changes.

\section{References}

Abe JI, Takahashi M, Ishida M, Lee JD \& Berk BC (1997) c-src is required for oxidative stress-mediated activation of mitogen activated protein kinase 1. Journal of Biological Chemistry 272, 20389-20394.

Adachi H \& Ishii N (2000) Effects of tocotrienols on life span and protein carbonylation in Caenorhabditis elegans. Journals of Gerontology, Series A. 55B, 280-285.

Adams GE, Willson RL, Aldrich JE \& Cundall RB (1969) On the mechanism of radiation induced inactivation of lysozyme in dilute aqueous solutions. International Journal of Radiation Biology 16, 333-342.

Aikawa R, Komuro I, Yamazaki T, Zhou Y, Kudoh S, Tanaka M, Shiojima I, Hiroi Y \& Yazaki Y (1997) Oxidative stress activated extracellular signals regulate kinases through src and ras in cultured cardiac myocytes of neonatal rats. Journal of Clinical Investigation 100, 1813-1821.

Anbar M \& Neta P (1967) A compilation of the specific bimolecular rate constants for the reactions of hydrated electrons, hydrogen atoms and hydroxyl radicals with inorganic compunds in aqueous solution. International Journal of Applied Radiation and Isotopes 18, 493-523.

Aviram M (2000) Review of human studies on oxidative damage and antioxidant protection related to cardiovascular disease. Free Radical Research 33, S85-S97.

Bates CJ, Chen SJ, MacDonald A \& Holden R (1996) Quantitation of vitamin E and a carotenoid pigment in cataractous human lenses, and the effect of a dietary supplement. International Journal for Vitamin and Nutrition Research 66, 316-321.

Buss H, Chan TP, Sluis KB, Domigan NM \& Winterbourne CC (1997) Protein carbonyl measurement by a sensitive ELISA method. Free Radical Biology and Medicine 23, 361-366.

Carp H \& Janoff A (1979) In vitro suppression of serum inhibitory elastase capacity by reactive oxygen species generated by phagocytosing polymorphonuclear leukocytes. Journal of Clinical Investigation 63, 793-797.

Carty JL, Bevan R, Waller H, Mistry N, Cooke M, Lunec J \& Griffiths HR (2000) The effects of vitamin C supplementation on protein oxidation in healthy volunteers. Biochemical and Biophysical Research Communications 273, 729-735.

Creed D (1984) The photophysics and photochemistry of the near UV absorbing amino acids III Cystine and its derivatives. Photochemistry and Photobiology 39, 577-583.

Dalton TP, Shertzer HG \& Puga A (1999) Regulation of gene expression by reactive oxygen. Annual Reviews in Pharmacology and Toxicology 39, 67-101.

Davies MJ, Fu S, Wang H \& Dean RT (1999) Stable markers of oxidant damage to proteins and their application in the study of human disease. Free Radical Biology and Medicine 27, 1151-1163.

Foy CJ, Passmore AP, Vahidassr MD, Young IS \& Lawson JT (1999) Plasma chain breaking antioxidants in Alzheimer's disease, vascular dementia and Parkinson's disease. Monthly Journal of the Association of Physicians, 92, 39-45.

Fu S, Davies MJ, Stocker R \& Dean RT (1998a) Evidence for roles of radicals in protein oxidation in advanced human atherosclerotic plaque. Biochemical Journal 333, 519-525.

Fu S, Gebicki S, Jessup W, Gebicki JM \& Dean RT (1995a) Biological fate of amino acid, peptide and protein hydroperoxides. Biochemical Journal 311, 821-827.

Fu S, Hick LA, Siel MM \& Dean RT (1995b) Structural identification of valine hydroperoxides and hydoxides on radical-damaged amino acid, peptide and protein molecules. Free Radical Biology and Medicine 19, 281-292.

Fu SL, Dean RT, Southan M \& Truscott R (1998b) The hydroxyl radical in lens nuclear cataractogenesis. Journal of Biological Chemistry 273, 28603-28609.

Funabiki R, Takeshita K, Miura Y, Shibasato M \& Nagasaw T (1999) Dietary supplement of rutin reduces oxidative damage in the rodent model. Journal of Agricultural Food Chemistry 47, 1078-1082.

Gius D \& Botero A (1999) Intracellular oxidation/reduction status in the regulation of transcription factors NF-kappaB and AP-1. Toxicology Letters 106, 93-106.

GIZZI Prevenzione Investigators (1999) Diet supplemented with n-3 polyunstaurated fatty acids and vitamin E after myocardial infarction; results from GIZZI Prevenzione Trial. Lancet 354, 447-455.

Gopalakrishna R \& Anderson WB (1987) Susceptibility of protein kinase C to oxidative inactivation: loss of both phosphotransferase activity and phorbol diester binding. FEBS Letters 225, 233-237.

Gopalakrishna R \& Anderson WB (1989) Calcium and phospholipid independent activation of protein kinase C by selective oxidative modification of the regulatory domain. Proceedings of the National Academy of Sciences USA 86, $6758-6762$.

Griffiths HR (2000) Antioxidants and protein oxidation. Free Radical Research 33, S47-S58.

Griffiths HR, Bevan R \& Lunec J (2000) Measurement of oxidised amino acids by HPLC. In Handbook of Oxidative Methods, pp. 27-50 [J Lunec \& HR Griffiths, editors] Oxford: John Wiley.

Griffiths HR \& Lunec J (1991) The effects of reactive oxygen species on immunoglobulin function. Molecular Aspects of Medicine 12, 107-119. 
Griffiths HR, Lunec J \& Blake DR (1992) Oxygen radical induced fluorescence in proteins; identification of the fluorescent tryptophan metabolite, N-formyl kynurenine, as a biological index of radical damage. Amino Acids 3, 183-194.

Griffiths HR, Wright J, Bevan R \& Lunec J (1999) Oxidative modification of a specific apolipoprotein B lysine residue confers altered receptor specificity on LDL. Redox Report 4, 85-88.

Grune T \& Davies KJ (1997) Breakdown of oxidised proteins as part of secondary antioxidant defences in mammalian cells. Biofactors 6, 165-172.

Hardwick JS \& Sefton BM (1997) Activation of the Lck tyrosine protein kinase by hydrogen peroxide requires the phosphorylation of tyrosine 394. Proceedings of the National Academy of Sciences USA 92, 4527-4531.

Hazell LJ, Davies MJ \& Stocker R (1999) Secondary radicals derived from chloramines of apolipoprotein B-100 contribute to HOCl-induced oxidation of low-density lipoproteins. Biochemical Journal 339, 489-495.

Hazen SL \& Heinecke JW (1997) 3-Chlorotyrosine, a specific marker of myeloperoxidase-catalyzed oxidation, is markedly elevated in low density lipoprotein isolated from human atherosclerotic intima. Journal of Clinical Investigation 99, 2075-2081.

Jacques PF, Taylor A, Hankinson SE, Willett WC, Mahnken B, Lee Y, Vaid K \& Lahav M (1997) Long term vitamin C supplement use and prevalence of early age-related lens opacities. American Journal of Clinical Nutrition 66, 739-740.

Jones AF \& Lunec J (1987) Protein fluorescence and its relationship to free radical activity. British Journal of Cancer, Suppl. 8, 60-65.

Kato Y, Mauyama W, Naoi M, Hashizume Y \& Osawa T (1998) Immuno-histochemical detection of dityrosine in lipofuscin pigments in the aged human brain. FEBS Letters 439, 231-234.

Kato Y, Miyake Y, Yamamoto K, Shimomura Y, Ochi H, Mori Y \& Osawa T (2000) Preparation of a monoclonal antibody to N(epsilon)-Hexanoyllysine: application to the evaluation of protective effects of flavonoid supplementation against exercise induced oxidative stress in rat skeletal muscle. Biochemical and Biophysical Research Communications 274, 389-393.

Keenoy BMY, Vertommen J \& DeLeeuw I (1999) The effect of flavonoid treatment on the glycation and antioxidant status in type I diabetic patients. Diabetes, Nutrition and Metabolism 12, 2556-2563.

Keyse SM \& Emslie EA (1992) Oxidative stress and heat shock induce a human gene encoding a protein-tyrosine phosphatase. Nature 359, 644-647.

Krapfenbauer K, Birnbacher R, Vierhapper H, Herkner K, Kampel D \& Lubec G (1998) Glycoxidation, and protein and DNA oxidation in patients with diabetes mellitus. Clinical Science 95, 331-337.

Lander HM, Hajjar DP, Hempstead BL, Mirza UA, Chait BT, Campbell S \& Quilliam LA (1997) A molecular switch on p21 ras. Structural basis for the nitric oxide-p21(ras) interaction. Journal of Biological Chemistry 272, 4323-4326.

Lander HM, Milbank AJ, Taurus JM, Hajjar DP, Hempstead BL, Schwartz GD, Kraemer RT, Mirza UA, Chait BT \& Burk E (1996) Redox regulation of cell signalling. Nature 381, 380-381.

Levine RL, Berlett BS, Moskovitz J, Mosoni LL \& Stadtman ER (1999) Methionine residues may protect proteins from critical oxidative damage. Mechanisms of Ageing and Development 107, 323-332.

Li N \& Karin M (1999) Is NF-kappaB the sensor of oxidative stress? FASEB Journal 13, 1137-1143.

Loft S \& Poulsen H (2000) Antioxidant intervention studies related to DNA damage, DNA repair and gene expression. Free Radical Research 33, S67-S83.

Lunec J \& Blake DR (1985) The determination of dehydroascorbate and ascorbic acid in the sera of patients with rheumatoid arthritis. Free Radical Research Communications 1, 131-139.

Lunec J, Blake DR, McCleary SJ, Brailsford S \& Bacon PA (1985) Self perpetuating mechanisms of immunoglobulin $\mathrm{G}$ aggregation in rheumatoid inflammation. Journal of Clinical Investigation 76, 2084-2090.

Luxford C, Dean RT \& Davies MJ (2000) Radicals derived from histone hydroperoxides damage nucleobases in RNA and DNA. Chemical Research in Toxicology 13, 665-672.

Luxford C, Morin B, Dean RT \& Davies MJ (1999) Histone H1 and other protein- and amino acid hydroperoxides can give rise to free radicals which oxidise DNA. Biochemical Journal 344, 125-134.

Manna SK, Sah NK \& Aggarwal BB (1998) Overexpression of MnSOD suppresses tumour necrosis factor-induced apoptosis and activation of nuclear transcription factor kappa B and activator protein 1. Journal of Biological Chemistry 273, 13245-13254.

Marangon K, Devaraj S, Tirosh O, Packer L \& Jialal I (1999) Comparison of the effect of alpha lipoic acid and alphatocopherol supplementation on measures of oxidative stress. Free Radical Biology and Medicine 27, 1114-1121.

Marchioli R (1999) Antioxidant vitamins and prevention of cardiovascular disease: laboratory, epidemiology and clinical trial data. Pharmacological Research 40, 227-238.

Margiloff L, Chaplia L, Chow A, Singhal PC \& Mattana J (1998) Metal catalysed oxidation of immunoglobulin G impairs Fc receptor mediated binding to macrophages. Free Radical Biology and Medicine 25, 780-785.

Methta J (1999) Antioxidants and prevention of cardiovascular disease: a debate. Canadian Journal of Cardiology 15, 26B-28B.

Mitomo K, Nakayama K, Fujimoto K, Sun X, Seki S \& Yamamoto K (1994) Two different cellular redox systems regulate the DNA binding activity of the p50 subunit of NF-kappa B in vitro. Gene 145, 197-203.

Morin B, Davies MJ \& Dean RT (1998) The protein product DOPA mediates oxidative DNA damage. Biochemical Journal 330, 1059-1067. 
Nemani R \& Lee EY (1993) Reactivity of sulphydryl groups of the catalytic subunits of rabbit skeletal muscle protein phosphatases 1 and 2A. Archives of Biochemistry and Biophysics 300, 24-29.

Nielsen SE, Young JF, Daneshvar B, Lauridsen ST, Knuthsen P, Sandström B \& Dragsted LO (1999) Effect of parsley (Petroselinium crispum) intake on urinary apigenin excretion, blood antioxidant enzymes and biomarkers for oxidative stress in human subjects. British Journal of Nutrition 81, 447-455.

Pierdomenico SD, Costantini F, Bucci A, DeCesare D, Bucciarelli T, Cuccurullo F \& Mezzetti A (1999) Blunted nocturnal fall in blood pressure and oxidative stress in men and women with essential hypertension. American Journal of Hypertension 12, 356-363.

Pirie A (1971) Formation of N-formylkynurenine in proteins from lens and other sources by exposure to sunlight. Biochemical Journal 125, 203-208.

Podmore, I, Griffiths HR, Herbert KE, Mistry N, Mistry P \& Lunec J (1998) Vitamin C exhibits pro-oxidant properties. Nature 392, 559.

Porkkala-Sarataho E, Salonen JT, Nyyssonen K, Kaikkonen J, Salonen R, Ristonmaa U, Diczfalusy U, Brigelius-Flohe R, Loft S \& Poulsen HE (2000) Long-term effects of vitamin E, vitamin C, and combined supplementation on urinary 7-hydro-8-oxo- $2^{1}$-deoxyguanosine, serum cholesterol oxidation products, and oxidation resistance of lipids in nondepleted men. Arteriosclerosis, Thrombosis and Vascular Biology 20, 2087-2093.

Powis G, Mustacich D \& Coon A (2000) The role of redox protein thioredoxin in cell growth and cancer. Free Radical Biology and Medicine 29, 312-322.

Qin S, Minami Y, Hibi M, Kurosaki T \& Yamamura H (1997) Syk dependent and independent signalling cascades in B cells elicited by osmotic and oxidative stress. Journal of Biological Chemistry 272, 2098-2103.

Rao GN (1996) Hydrogen peroxide induces complex formation of Shc-Grb2-SOS with receptor protein tyrosine kinase and activates ras and extracellular signal regulated protein kinase group of mitogen activated protein kinases. Oncogene 13, 713-719.

Reinheckel T, Sitte N, Ullrich O, Kuckelkorn U, Davies KJ \& Grune T (1998) Comparative resistance of the 20S and 26S proteosome to oxidative stress. Biochemical Journal 335, 637-642.

Riciarelli R, Zingg JM \& Azzi A (2000) Vitamin E reduces the uptake of oxidised LDL by inhibiting CD36 scavenger receptor expression in cultures aortic smooth muscle cells. Circulation 102, 82-87.

Robinson S, Bevan R, Lunec J \& Griffiths HR (1998) Chemiluminescence determination of hydroperoxides following radiolysis and photolysis of free amino acids. FEBS Letters 430, 297-300.

Ruff SJ \& Chen K (1997) Peroxovanadate induces tyrosine phosphorylation of multiple signalling proteins in mouse liver and kidney. Journal of Biological Chemistry 272, 1263-1267.

Schreck R, Albermann K \& Baeuerle PA (1992) Nuclear factor kappa B: an oxidative stress responsive transcription factor of eukaryotic cells (a review). Free Radical Research Communications 17, 221-227.

Simon E, Paul JL, Soni T, Simon A \& Moatti N (1997) Plasma and erythrocyte vitamin E content in asymptomatic hypercholesterolemic subjects. Clinical Chemistry 43, 285-289.

Simon JA (1992) Vitamin-C And Cardiovascular-Disease - A Review. Journal of the American College of Nutrition 11, $107-125$

Singh A, Antonsen SA \& Koroll GW. (1984) Radiolysis and photolysis of aerated tryptophan solutions. In Oxygen Radicals in Chemistry and Biology, pp. 461-500 [W Bors, M Saran \& D Tait, editors]. Berlin: Walter Gruyter and Co.

Srigiridhar K \& Nair KM (2000) Supplementation with $\alpha$-tocopherol or a combination of tocopherol and ascorbic acid protects the gastrointestinal tract of iron-deficient rats against iron-induced oxidative damage during iron repletion. British Journal of Nutrition 84, 165-173.

Stadtman ER (1993) Oxidation of free amino acids in proteins by radiolysis and metal catalysed reactions. Annual Reviews in Biochemistry 62, 797-821.

Stadtman ER \& Oliver CN (1991) Metal catalysed oxidation of proteins. Journal of Biological Chemistry 266, 2005-2008.

Steinberg D, Partharasarathy S, Carew TE, Choo JC \& Witzum JL (1989) Beyond cholesterol. Modifications of low density lipoprotein that increase its atherogenicity. New England Journal of Medicine 320, 915-924.

Steinbrecher UP (1999) Receptors for oxidised low density lipoprotein. Biochimica Biophysica Acta 1436, $279-298$.

Steinbrecher UP, Zhang H \& Lougheed MR (1990) Role of oxidatively modified LDL in atherosclerosis. Free Radical Biology and Medicine 9, 155-168.

Stephens NG, Parsons A, Schofield PM, Kelly F, Cheeseman K \& Mitchinson MJ (1996) Randomised control trial of vitamin $\mathrm{E}$ in patients with coronary heart disease; Cambridge Heart Antioxidant Study (CHAOS). Lancet 347, 781-786.

Tessier F, Moreaux V, BirlouezAragon I, Junes P \& Mondon H (1998) Decrease in vitamin C concentration in human lenses during cataract progression. International Journal for Vitamin and Nutrition Research 68, 309-315.

Tribble DL (1999) Antioxidant consumption and risk of coronary heart disease: emphasis on vitamin C, vitamin E and $\beta$-carotene. A statement for healthcare from the American Heart Association. Circulation 99, 591-595.

Tsimikas S, Shortal BP, Witztum JL \& Palinski W (2000) In vivo uptake of radiolabeled MDA2, an oxidation-specific monoclonal antibody, provides an accurate measure of atherosclerotic lesions rich in oxidized LDL and is highly sensitive to their regression. Arteriosclerosis, Thrombosis, and Vascular Biology 20, 689-697. 
Viner RI, Williams TD \& Schöneich C (2000) Nitric oxide-dependent modification of the sarcoplasmic reticulum CaATPase: localization of cysteine target sites. Free Radical Biology and Medicine 29, 489-496.

Wander RC \& Du SH (2000) Oxidation of plasma proteins is not increased after supplementation with eicosapentaenoic acids and docosahexaenoic acids. American Journal of Clinical Nutrition 72, 731-737.

Wang X, Culotta VC \& Klee CB (1996) Superoxide dismutase protects calcineurin from inactivation. Nature 383, 434-437.

Weber C, Draude G, Weber KSC, Wubert J, Lorenz RL \& Weber PC (1999) Down-regulation by tumour necrosis factor alpha of monocyte CCR2 expression and monocyte chemotactic protein-1 induced transendothelial migration is antagonised by oxidised low density lipoprotein - a potential mechanism of monocyte retention in atherosclerotic lesions. Atherosclerosis 145, 115-123.

Winterbourne CC, Chan T, Buss IH, Inder TE, Mogridge N \& Darlow BA (2000) Protein carbonyls and lipid peroxidation products as oxidation markers in pre-term infant plasma: Associations with chronic lung disease and retinopathy and effects of selenium supplementation. Pediatric Research 48, 84-90.

Witzum JL \& Steinberg D (1991) Role of oxidised low density lipoprotein in atherogenesis. Journal of Clinical Investigation 88, 1785-1792.

Xanthoudakis S \& Miao G (1992) Redox activation of Fos-Jun DNA binding activity is mediated by a DNA repair enzyme. EMBO Journal 11, 3323-3335.

Young JF, Dragsted LO, Daneshvar B, Lauridsen ST, Hansen M \& Sandstrom B (2000) The effect of grape skin extract on oxidative status. British Journal of Nutrition 84, 505-513.

Young JF, Nielson SE, Haraldsdottir J, Daneshvar B, Lauridsen ST, Knuthsen P, Crozier A, Sandstrom B \& Dragsted LO (1999) Effect of fruit juice on urinary quercetin excretion and biomarkers of antioxidative status. American Journal of Clinical Nutrition 69, 87-94. 
British

Journal of

Nutrition

\section{Editor-in-Chief}

Professor Paul Trayhurn

Department of Medicine,

University of Liverpool, UK

\section{Deputy Editors}

P S Shetty (ltaly),

T M S Wolever (Canada)

\section{Reviews Editor}

A G Dulloo (Switzerland)

Supplements Editor

K N Frayn (UK)

\section{Books Editor}

G P Webb (UK)

Supported by an International

Editorial Board representing each of the subject specialties in

nutritional science.

To order your subscription contact:

\section{CABI Publishing,}

CAB International,

Wallingford,

Oxon, OX10 8DE, UK

Tel: +44 (0)1491832111

Fax: +44 (0)1491 829292

Email: publishing@cabi.org

\section{CABI Publishing,}

$C A B$ International,

10 East 40th Street,

Suite 3203,

New York, NY 10016, USA

Tel: 2124817018

Toll free: 8005284841

Fax: 2126867993

Email: cabi-nao@cabi.org
Available on the Internet at

www.cabi-publishing.org/journals

The British Journal of Nutrition is an international, peer reviewed journal publishing original papers, review articles, short communications and commentaries on human and clinical nutrition, animal nutrition and basic nutritional science. Correspondence is encouraged in a nutrition discussion forum.

The journal recognises the multidisciplinary nature of nutritional science and invites the submission of material from all of the specialties in nutrition research. The journal also publishes supplements on topics of particular interest.

\section{Coverage includes:}

- Molecular Nutrition and Gene Expression

- Metabolism and Metabolic Studies

- Nutritional Immunology

- Body Composition

- Dietary Surveys and Nutritional Epidemiology

- Neurobiology

- Nutritional Energetics

- Behaviour

- Nutrient Requirements

- Obesity

\section{Special features:}

- Book Reviews

- Short Communications

- Commentaries

- Letters to the Editor

\section{Supplements:}

Supplements are also published on topics of particular current interest and provided free to all subscribers.

\section{Forthcoming supplements include:}

\section{2, Volumes $87 / 88$}

12 issues per year plus supplements

$\begin{array}{lll}\text { Print only } & \text { Internet only } & \begin{array}{l}\text { Print/Internet } \\ \text { Package }\end{array} \\ £ 475.00 & £ 465.00 & £ 490.00 \\ \$ 830.00 \text { Americas only } & \$ 815.00 \text { Americas only } & \$ 860.00 \text { Americas only } \\ 760.00 \text { EU only } & 740.00 \text { EU only } & 780.00 \text { EU only }\end{array}$

